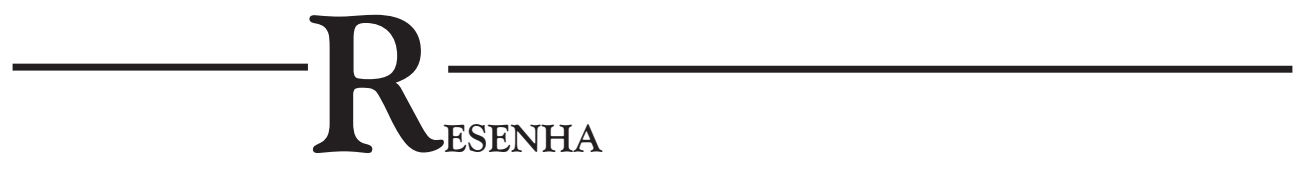

ORO, Ari Pedro; RICKLI, João; STEIL, Carlos Alberto (ed.). Transnacionalização Religiosa: Fluxos e Redes. São Paulo: Editora Terceiro Nome, 2012, 206pp.

\title{
TECENDO REDES TRANSNACIONAIS COM FIOS TRANSCENDENTAIS
}

\section{Cleonardo Maurício Júnior}

Universidade Federal de Pernambuco

Recife - Pernambuco - Brasil

Poucos discordariam que acompanhar crenças e práticas de fenômenos religiosos distintos, cruzando fronteiras em várias direções, estaria entre os requisitos necessários para se falar apropriadamente acerca da transnacionalização religiosa. Empreitada amplamente cumprida por esta coletânea, fruto de um acordo transnacional entre o Programa de Pós-Graduação em Antropologia da Universidade Federal do Rio Grande do Sul e o departamento de Ciências Sociais da Universidade Livre de Amsterdã. A descrição de fluxos entre Argentina e Brasil, de deslocamentos do Brasil a Moçambique, da Irlanda à França e à Bósnia e de volta, da Holanda ao Brasil e do Brasil à Holanda, bem como de redes envolvendo o México e os Estados Unidos, garante a abrangência geográfica das etnografias contidas nesta obra. $\mathrm{O}$ debate dos autores acerca de fenômenos religiosos, tais como o pentecostalismo, protestantismo, catolicismo tradicional e carismático, além do espiritismo, assegura também uma variedade 
considerável de religiões discutidas. No entanto, pode-se apontar uma ressalva quanto a esta questão, na medida em que o livro trata mais propriamente de uma transnacionalização do cristianismo, presente até mesmo no espiritismo cristão brasileiro, e não contempla uma discussão, por exemplo, sobre os movimentos de cunho new age, o Islã, o budismo, entre outros. E, mesmo ao tratar do âmbito cristão, metade da obra é dedicada ao pentecostalismo, o que pode ser justificado, porém, pelo maior esforço deste movimento em consolidar sua presença globalmente.

Podem-se apresentar as contribuições desta obra ao tema da transnacionalização religiosa a partir de dois eixos. O primeiro, uma contraposição entre trabalhos que enfatizam as estratégias dos atores nodais para construírem e se movimentarem nas redes transnacionais, o que chamo de transnacionalização por cima, e os trabalhos que apresentam a transnacionalização por baixo, on the ground, mostrando como as religiões oferecem esquemas de significação que permitem a transcendência do local e concedem um suporte adequado à vida em contexto transnacional. No segundo eixo, aponto como alguns trabalhos da coletânea nos permitem pensar em pertencimentos locais, que são reforçados mesmo com a adesão a movimentos transnacionais.

Um exemplo significativo do que chamo de transnacionalização por cima é apresentado por Daniel Alves e Ari Pedro Oro no capítulo O pentecostalismo globalizado das pequenas e médias igrejas: contribuição ao estudo de redes religiosas transnacionais. Os autores tratam de uma rede transnacional formada por pastores argentinos, tendo sua influência estendida a pequenas e médias igrejas pentecostais de Porto Alegre e Montevidéu. Apontar este caminho ilumina um processo situado geralmente à sombra do movimento inverso, que diz respeito às megaigrejas brasileiras, como a Igreja Universal do Reino de Deus (IURD), internacionalizando-se em direção ao Mercosul, haja vista a dimensão grandiosa destas instituições. A rede formada por pastores argentinos e brasileiros, segundo os autores, é baseada em relacionamentos pessoais e resulta de um processo engendrado por uma lógica concorrencial. O que se procura é uma legitimação simbólica adquirida a partir da movimentação nesta rede, através da participação em eventos como conferências internacionais ou em campanhas massivas localizadas em lugares públicos. Atuando como referências espirituais para os pastores de Porto Alegre, os sacerdotes argentinos vêm a estes eventos como conferencistas, alargando sua influência em solo brasileiro, o que não gera, necessariamente, uma contraprestação (um convite ao pastor brasileiro para ser conferencista de um evento em terreno argentino), caracterizando-se assim, como dizem os autores, uma relação unilateral.

Mesmo afirmando que a concretização destes contatos só se dá através de uma "coesão discursiva" (:26), um idioma em comum assentado no sistema simbólico pentecostal, o que se vê neste modelo de transnacionalização proposto pelos autores é a construção de uma rede sendo formada a partir de contatos políticos engendrados pelos líderes do processo. Já com o trabalho de Linda Van den Kamp, sobre a adesão de mulheres moçambicanas à IURD (Pentecostalismo brasileiro, "macumba" e mulheres urbanas em Moçambique), pode-se perceber o sistema simbólico pentecostal agindo on 
the ground na vida dos convertidos. O objetivo da autora é "obter uma visão clara de como e por que o pentecostalismo brasileiro atrai tantos seguidores na África austral" (:60). Van den Kamp aborda a conversão de mulheres moçambicanas e mostra que a atração pelo pentecostalismo brasileiro se dá devido à ascensão econômica destas. $\mathrm{O}$ pentecostalismo proporcionaria a possibilidade de superação da imobilidade encontrada no espaço urbano de Maputo ao se aderir à mobilidade transnacional oferecida pela IURD. Este deslocamento é subjetivo. As mulheres moçambicanas assumem o que a autora chama de posicionamentos transnacionais quando rompem com a cultura moçambicana no que diz respeito, principalmente, à rejeição aos espíritos locais (declarados como malignos e responsáveis por prováveis insucessos nos negócios) e à forma de gerir seus afetos (os pastores brasileiros incentivam demonstrações públicas de afeto, reprovadas na cultura local).

Carlos Alberto Steil e Ana Paula Pimentel Walker, em Ser Carismático e hispânico em San Diego, Califórnia, apresentam a Renovação Carismática Católica (RCC) como apropriada para oferecer aos hispano-americanos "um suporte semântico e social para o trânsito contínuo entre dois domínios culturais" (:163). Formada majoritariamente por hispânicos, a RCC permitiria aos que habitam a fronteira entre os EUA e o México, e que transitam continuamente entre San Diego e Tijuana, chegando até a possuir residências em ambos os locais, construir simbolicamente um terceiro espaço (:165). Este novo espaço se caracterizaria por ir além da ortodoxia do Vaticano, representada pela paróquia americana local, e pela superação de formas sincréticas do catolicismo tradicional mexicano. Assim, como no caso da conversão das mulheres moçambicanas, ocorre o que os autores da Introdução (onde se tenta dar uma uniformidade teórica ao livro) afirmam ser o principal aspecto da transnacionalização: a reterritorialização $(: 8,9)$. Converte-se a algo que transcende a localidade em busca de uma forma mais adequada de se adaptar à modernidade ocidental, deixando para trás os espíritos locais que atrapalham os empreendimentos urbanos de Moçambique, ou, no caso da RCC, livrando-se tanto do institucionalismo das paróquias americanas quanto das crenças indígenas e rituais mágicos do catolicismo tradicional mexicano. O paradoxal, no entanto, assim entendo, é que esta adesão à modernidade ocidental se dá através da hipervalorização de experiências extra-cotidianas (para não dizer mágicas), na medida em que se livra da ação dos espíritos ancestrais em Moçambique, ou se exorciza a influência maligna representada pelas crenças tradicionais mexicanas em San Diego.

Se em Moçambique aderir ao pentecostalismo é converter-se ao "Espírito Santo transnacional" (:74), e em San Diego a RCC está apta a receber fiéis em contexto de mobilidade, nas currutelas amazônicas (pequenas comunidades próximas às minas de garimpo), por sua vez, esta relação mobilidade versus imobilidade aparece invertida. Eline de Smet, Leticia Tedesco e Marjo De Theije (Viver nas currutelas pan-amazônicas: consumo conspícuo e religião em garimpos transnacionais), mostram que, nas regiões de garimpo, converter-se ao pentecostalismo é aderir à fixidez. É abandonar o consumo conspícuo relacionado à aquisição de prestígio entre as mulheres, deixando a vida 
nômade de garimpo a garimpo em busca de riqueza, e fixando-se na currutela, constituindo família. Tal constatação nos permite questionar se, mais do que impulsionar a mobilidade afinada com a modernidade, o pentecostalismo não se caracterizaria, acima de tudo, por ser uma cultura contra a cultura, realizando o que Robbins ${ }^{1}$ chama de demonização dos símbolos locais, onde quer se instale. A partir deste modus operando, a ritualização cotidiana do embate contra os espíritos locais ${ }^{2}$, o pentecostalismo pode "viajar bem" ${ }^{3}$ uma vez que sempre é bem-sucedido em alcançar um sentido local, significando coisas diferentes em locais diferentes.

Quando se compara o pentecostalismo ao seu ancestral, os dados relativos ao protestantismo tradicional geralmente são datados, já que poucas pesquisas em solo brasileiro têm se dedicado a esta tradição. João Rickli, em Missionários e imigrantes: alteridade, engajamento e experiência em dois modos distintos de transnacionalização religiosa, preenche esta lacuna e mostra a rígida construção de fronteiras simbólicas efetuada pelas comunidades de imigrantes holandeses protestantes. A Igreja Evangélica Reformada (IER), estabelecida em comunidades do sul e sudeste do Brasil, é, diz o autor, uma igreja de parentes. A IER orgulha-se de não praticar tipo algum de proselitismo e tende a não atrair novos membros brasileiros. A missão, neste caso, torna-se sinônimo de migração: "a existência das colônias e a vida cotidiana dos seus membros são investidas de um caráter religioso e interpretadas como missionárias por natureza" (:95). A missão dos imigrantes é obter sucesso econômico e tornar a terra produtiva, ou seja, torná-la melhor a partir de sua simples presença. Não há, como entre os pentecostais e carismáticos, um sentimento de urgência em alcançar o globo a partir de um proselitismo massivo. Este pode ser considerado um diferencial significativo para o sucesso da ubiquidade pentecostal no mundo globalizado.

Bernardo Lewgoy, no capítulo Entre herança européia e hegemonia brasileira: notas sobre o novo kardecismo transnacional, investe, majoritariamente, na explicação da transnacionalização do espiritismo brasileiro a partir de uma rede construída por cima, nos mesmos moldes do que fazem Alves \& Oro acerca da expansão das igrejas argentinas em direção ao sul do Brasil. Neste texto, o autor afirma que é o modelo brasileiro de prática do espiritismo, mais cristão, que está sendo globalizado. Lewgoy menciona ainda uma mudança indispensável, catalisadora da expansão do espiritismo brasileiro no âmbito internacional: a alternância da ênfase em uma "religião baseada na dor e no sacrifício" em direção a um "modelo bem-estarista, centrado nos temas da saúde e da felicidade" $(: 105,106)$. Aponta-se também que o modelo burocrático do espiritismo globalizado segue os moldes da Federação Espírita Brasileira, sendo os principais agentes globalizantes da doutrina espírita os imigrantes brasileiros, sobretudo mulheres de classe média casadas com estrangeiros. Mas é necessário ir a outros trabalhos de Lewgoy ${ }^{4}$ para se entender como o sistema simbólico confirmaria sua eficácia em oferecer recursos a estas imigrantes, permitindo que lidem com a sociedade de acolhida.

Transcender a localidade a partir de uma conexão com um movimento mais amplo, que se pretende universal, não significa, necessariamente, a rejeição de iden- 
tidades locais. Os peregrinos irlandeses de Donegal apresentados por Judith Kolen (Ritual e comunidade: a experiência da peregrinação em Donegal, Irlanda), por exemplo, ao se deslocarem para os santuários de Medjugorje na Bósnia, ou Fátima, na França, estão se engajando, segundo a autora, em rituais de demarcação de fronteiras comunitárias. Engajar-se na peregrinação e intensificar a identidade de católico é, ao mesmo tempo, reforçar a pertença a Donegal, já que ser católico, mesmo em tempos de secularização, diz a autora, "ainda é parte da herança cultural e do sentimento de 'self' dos irlandeses" (:141). Este reforço das identidades locais pode assumir traços agonísticos, como mostra o conflito entre católicos portugueses e brasileiros numa paróquia holandesa apresentado por Andrea Damacena Martins em Relocalização da religião em contexto transnacional: o caso da Igreja Católica de língua portuguesa em Haia, Holanda. O conflito entre estas comunidades para que se dê um maior prestígio a Nossa Senhora de Fátima, dos portugueses, ou a N. S. Aparecida, dos brasileiros, lança luz sobre o fato de que nem sempre adesões a movimentos e fenômenos globais suplantam identidades locais.

A obra em questão apresenta, assim, as diversas estratégias de transnacionalização dos movimentos religiosos e as várias formas como estes movimentos se mostram aptos a conectar o fiel a algo pretensamente universal, providenciando suporte simbólico para situações de transnacionalização ou oferecendo acesso à modernidade globalizada, refazendo o sentido de território dos seguidores em direção à transcendência do local. Em algumas ocasiões, transcender o local, paradoxalmente, é reforçar as identidades construídas a partir deste prisma. Mesmo sentindo falta de uma discussão acerca dos limites impostos aos fluxos transnacionais ${ }^{5}$, a fim de se entender quais culturas são mais ou menos refratárias e a quais fluxos, a leitura desta obra é imensamente recomendada para os que pretendem compreender as singularidades da construção das redes religiosas transnacionais e como, principalmente, tais redes fisgam os fiéis, atraindo-os para uma possibilidade de aprender um idioma global e movimentar-se em direção à transcendência, ainda que, em termos estritamente geográficos, não se saia do lugar.

\section{Notas}

1 OBBINS, Joel. ((2004). "The Globalization of Pentecostal and Charismatic Christianity". Annual Review of Anthropology, n 33: 117-143.

2 EYER, Birgit. (1998), "Make a Complete Break with the Past". Journal of Religion in Africa, no 3: 316349.

3 CSORDAS, Thomas. (2009), "Introduction: Modalities of Transnational Transcendence". In: T. Csordas (ed.). Transnational Transcendence: Essays on Religion and Globalization. Berkeley and Los Angeles: University of California Press.

4 LEWGOY, Bernardo. (2008), "A transnacionalização do Espiritismo Kardecista Brasileiro: uma discussão inicial". Religião e Sociedade, nº1: 84-104. 
5 HANNERZ, Ulf. (1997), "Fluxos, Fronteiras, Híbridos: Palavras-Chave da Antropologia Transnacional". Mana, no1: 7-39.

Cleonardo Mauricio Junior (cleonardobarros@gmail.com) Mestrando do Programa de Pós-Graduação em Antropologia da Universidade Federal de Pernambuco e pesquisador do Núcleo de Pesquisa das Religiosidades Populares (NERP PPGA-UFPE). 